\title{
Wind Energy Technologies for Distributed Power
}

\author{
L. El Chaar ${ }^{1}$ and L.A. Lamont ${ }^{2, *}$ \\ ${ }^{1}$ Power Generation Services Product Line Manager, GE Power \& Water, Dubai, UAE \\ ${ }^{2}$ Power System Analysis Engineer, Transmission and Distribution Division, Mott MacDonald, Glasgow, \\ Scotland
}

\begin{abstract}
This paper is an industrial update on the development of wind energy conversion systems (WECS). It highlights the two major types of wind turbines: horizontal axis and vertical axis. To enhance the integration and deployment of wind technologies, advancements in their operation have been developed specifically with regard to enhanced efficiency, making them more robust and less susceptible to wind variations. This paper encapsulates the various power ratings available in the range of $10 \mathrm{~kW}$ to $1 \mathrm{MW}$ while providing manufacturer and technical details of such topologies. The paper also considers the future requirement potential of wind energy technology.
\end{abstract}

Keywords: Renewable Energy, Horizontal Axis Wind Turbine, Vertical Axis Wind Turbine, H-rotor Wind Turbine, Wind Energy conversion Systems.

\section{INTRODUCTION}

The rapidly growing demand for electrical energy, the constraint on pollution levels and the limitation on fossil fuel reserves and supply have led to a rising interest in researching and utilization of renewable energy sources and technologies. The reduction of $\mathrm{CO}_{2}$ emissions as well as the expanding power demand has lead to the embracement of renewable energy technologies (RET) [1].

Renewable energy can be defined as "energy obtained from the continuous or repetitive currents of energy recurring in the natural environment" [2]. Wind, an indirect form of solar energy caused by the uneven heating of the earth's surface, is an environmentallyfriendly source and has become a major contributor in power generation, both onshore and offshore. The amount of installed wind power is increasing as it provides future security in the national energy supply due to the decreasing availability of fossil fuels which threatens the long term global economy [3]. To overcome this, research and development is ongoing on various wind energy conversion systems (WECS), ranging from a few kilowatts to megawatts. This output specification is dependent on turbine diameter and blade length parameters which affect the rotor's swept area. To ensure a full investigation of wind technology, studies are presented into the two main types of WECS which are based on the orientation axis of rotation, namely horizontal axis wind turbines (HAWT) and vertical axis wind turbines (VAWT). This paper

*Address correspondence to this author at the Power System Analysis Engineer, Transmission and Distribution Division, Mott MacDonald, Glasgow, Scotland; Tel: +44(0)141 222 9162; Fax: +44(0)141221 2048;

E-mail: lisa.lamont@mottmac.com presents a short historical overview of wind power, and then specifically discusses the various technologies available in the range of $10 \mathrm{~kW}$ to $1 \mathrm{MW}$ output power, these being mainly used in distributed power generation systems. The main interest and growth in such power rated technology is due to the higher consumer demand, the increase in government incentives and the recognition that investment in small wind turbines can be an enduring source of economic development for the rural locales in which they are typically deployed [4]. All these factors are accelerating the growth for the small wind power market. Power users are identifying the benefits of wind distributed generation as it represents a great economic solution, particularly in rural areas or underdeveloped regions with abundant local resources.

\section{BACKGROUND}

Historically, wind was traditionally used for transportation (sailing boats) and human survival (grinding grain, pumping water, etc) [5]. Primarily, windmills were VAWTs but HAWTs were further developed in the middle ages and became more dominant [6]. WECS, no matter whether horizontal or vertical, both depend on aerodynamic lift [7] using blades to interact with the incoming wind and perform the necessary kinetic-to-electrical energy conversion. In 1888, the first attempt to generate electricity in the United States (US) using a windmill to charge storage batteries was achieved by Charles Brush [5]. During the $20^{\text {th }}$ century HAWT design progressed, which resulted in larger and more advanced turbines. Meanwhile, VAWTs were also evolving, but at a slower rate due to lack of commercial and engineering interest and financial support. 
Over the last decade significant developments have been made in upgrading and up-scaling small turbine designs. While the rotor diameter and hub height have both increased, the weight per swept area, the weight of the tower and the rotor weight have all decreased. These modifications in the rotor led to an improvement in performance, giving an efficiency increase from $35 \%$ in the early 1980 s to $48 \%$ in the mid nineties. Such advancement has made it possible to capture more wind, and hence produce more electricity per unit rotor area. Recently the technical availability of such systems has been boosted to $98 \%$ [8-11]. In relation to wind turbines the load factor is an important consideration as it describes how much power is produced which obviously varies from one site to another as well as when the wind speeds fluctuate. The load factor is recognized as the measure for the percentage of a theoretical maximum output of $24 \mathrm{hrs}$ a day, 365 days a year that a particular generating plant or technology attains - on average, onshore wind load factors reaches $26 \%$.

Currently, both horizontal and vertical axis wind turbine designs are efficient; however, both technologies have faced several challenges related to loading and size increase and are consequently undergoing rigorous testing and improvements [12]. Wind availability, influence of the height of the installation above ground, as well as gust effect, are the main factors which impact on the amount of output energy generated $\mathrm{P}_{\mathrm{WT}}$ by WECS [13]

$P_{W T}=\frac{1}{2} C_{p} \pi R^{2} \rho v^{3}$

Where $C_{P}$ is the wind power coefficient which defines how much of the energy in the wind is absorbed by the machine, $R$ is the rotor blade radius $(\mathrm{m}), \rho$ is the wind density $\left(\mathrm{Kg} / \mathrm{m}^{3}\right)$ and $v$ is the wind speed $(\mathrm{m} / \mathrm{s})$. The latter's variation is given by [14]:

$v=v_{0}\left(\frac{h}{h_{0}}\right)^{\alpha}$

Where $v_{o}$ is the recorded wind speed at $h_{0}$ height, $v$ is the wind speed to be determined at height $h$ and $\alpha$ is the surface roughness class.

Normally, $C_{P}$ is smaller in VAWTs than in HAWTs since it is a function of the blade pitch angle and the tip speed ratio $\lambda$, defined as [13]:

$\lambda=\frac{\omega R}{v}$
Where $\omega$ is the rotational frequency of the turbine.

The potential of a wind turbine to extract power from varying wind, which is important in generation, is a function of three main factors: power availability, characteristic curves provided by the manufacturer (principally output power versus wind speed) and the capability of the turbine to withstand wind fluctuations. Hence, wind energy machine design is highly dependent on the WECS type selected and its power curve. Turbine type is considered further in the following sections, taking into account output power, ease of build/maintenance, environmental impact and cost.

\section{VERTICAL AXIS WIND TURBINE}

This type of turbine was initially invented by Darrieus, a French Engineer who specified in his initial patent two possible options: a symmetrically curved blade set (Darrieus - Figure 1a) and a straight bladed unit (H-rotor - Figure 1b) [15].

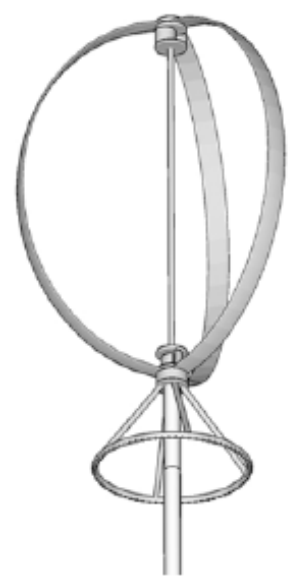

(a)

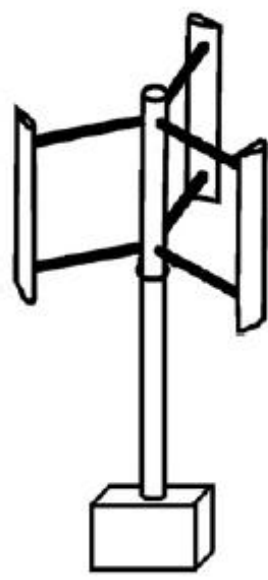

(b)
Figure 1: Veratical Axix Wind Turbine a) Darrieus and b) $\mathrm{H}$ rotor.

This technique presented a major advantage over other technologies because of its simplicity, with wind direction having no impact on either. The advantages and disadvantages of the VAWT are summarized below:

\section{Advantages}

- omni-directional, hence no power losses during short gusts

- $\quad$ as the angle of the wind-to-blade contact in not important in this system it can be placed in turbulent and wind-varying locations 
- $\quad$ positioning of the generator and controller can be at the bottom of the tower, making it highly accessible for maintenance, installation and operation

- less noisy hence very suitable for roof top application in residential areas

- the Darrieus design is not structurally top-heavy

- $\quad$-rotors are readily manufactured in quantity at low cost

- no yaw control system is required, further reducing cost and failure factor

- the structure can be lighter as no nacelle is included, so reducing construction and loading requirements [16]

- $\quad$ guide ropes can be used for structural shaft support, hence reducing the requirements on the external supporting tower

- the Darrieus type requires only simple foundations for the system

- $\quad$ vertical turbines are considered more suitable for offshore application, but are currently only available for low power

- H-rotor is less harmful for birds and bats because of slow blade rotation [17]

- $\quad$ less problems with icing

- $\quad$ reduced security area between towers

- this technology is robust

\section{Disadvantages}

- $\quad$ challenges under stalled conditions, such as the poor starting torque at high angles of wind attack [18]

- $\quad$ intrinsic torque ripple affecting the fatigue life of the drive, as well as the output power quality [16]

- $\quad H$-rotor blade area is larger, hence more material is used [16]

- $\quad H$-rotor blades are subject to bending moments: these do decrease as the size of wind turbine increases since the centripetal acceleration diminishes with augmenting turbine radius for a constant speed [19-21]
- $\quad$ for the Darrieus type, pitch control is not possible [22]

- Darrieus blades are relatively complex to manufacture and relocate [18].

Some of these issues have been investigated and solutions developed. To combat poor starting, two principles can be employed: either a blade profile or pitching mechanism can be used, or for a gridconnected system the turbine can be spun up to speed by initially connecting the generator as a motor [23]. By increasing the number of blades to three or more, torque ripples are reduced [24], and variable speed drives can be integrated into the system as another option to improve output quality [18]. To avoid overspeeding of the turbine, Musgrove proposed a variable geometry H-rotor VAWT where blades could be folded towards the horizontal in high winds to reduce the presented area [24]. This is complex mechanically, and a simplified structure is normally preferred with a control system used to induce a stall at higher speeds, causing a reduction in absorbed power.

Even considering these complicating factors, several companies are developing products based on VAWT technology.

\section{HORIZONTAL AXIS WIND TURBINES}

Currently, horizontal axis technology (Figure 2) dominates the wind energy applications market. It too has positive and negative characteristics:

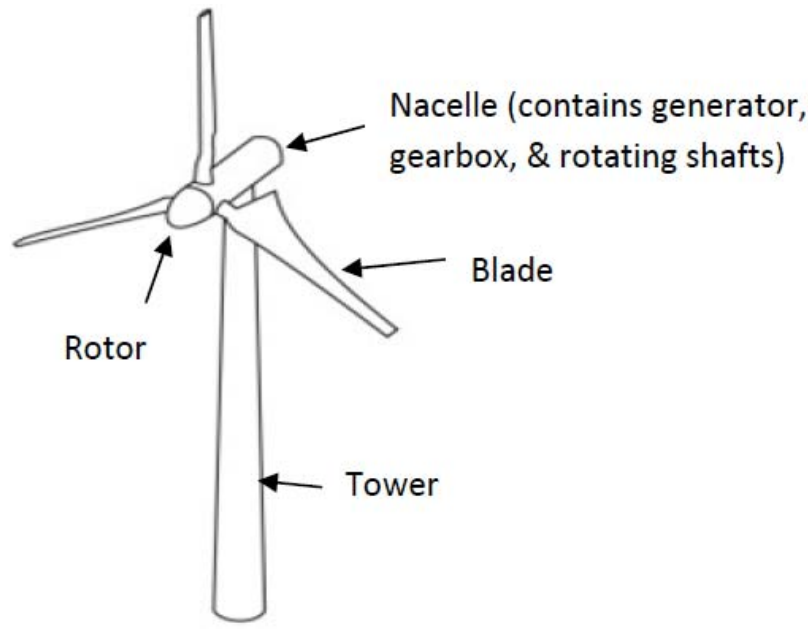

Figure 2: Horizontal Axix Wind Turbine.

\section{Advantages}

- fewer blades (two or three) than those used in VAWT 
- blades are self-supported since they are only attached at the root - the result is a lighter top, giving a reduction in the cost of the structure

- $\quad$ self-starting at a low wind speed

- $\quad$ pitch control is possible for output power control and to stop the turbine when needed

- $\quad$ currently lower cost due to mass production

\section{Disadvantages}

- issues such as noise and tower interference caused by the tower's shadow

- complicated structure as it contains a yaw mechanism and active stall regulation

- more exposed to periodic loads which could reduce their lifetime

- limitation on maximum power production due to system constraints (body, blades, hub height)

- maintenance is demanding.

Some HAWT disadvantages are currently being solved. For example, to overcome the noise or humming generated by the machines a planning solution is to place wind farms far from residential areas (at least $300 \mathrm{~m}$ away) as shown in Figure 3 [26], or add an active damping system which senses the change in frequency and neutralizes the noise without affecting the speed of the wind generator. Piezo actuators are the key constituents of this system [27]. Piezo actuator converts electric current into mechanical motion and generate "negative vibrations", or a kind of anti-noise that precisely counteracts the vibrations of the wind turbine and cancels them out.

Maintenance issues can be reduced by using a direct drive wind generator and removing the gearbox as it is one of the main components subject to failure which can cause turbine down-time [28]. However, it must be noted that this increases the cost and the size of the turbine.

Considering such features, HAWT design has diversified, based on three different approaches [2830]. The first concentrates on the issue of high wind loads, the second design ensures the capability of accommodating shed loads, and the third technique describes turbines which are intended to manage loads mechanically and/or electrically. Several companies have invested in combining the various important approaches, but currently the third method dominates the marketplace.

Irrespective of the turbine orientation selected for future power distribution systems, manufacturing company specifications have a vital input to the final build.

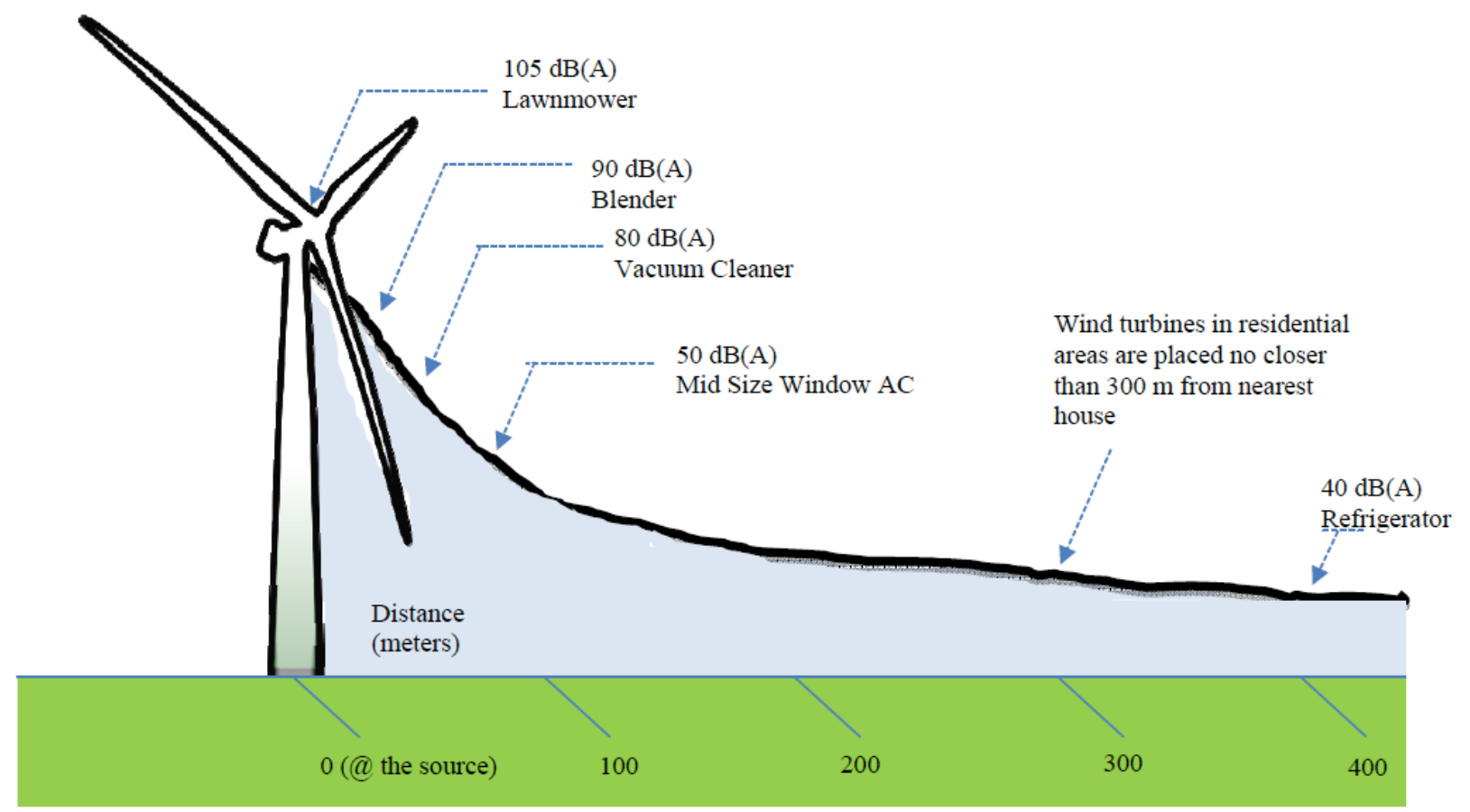

Figure 3: Noise of Wind Turbines by GE [26]. 


\section{EMBRACING WIND FOR POWER GENERATION}

Small turbines, with power ratings below $100 \mathrm{~kW}$, are mostly dedicated to power up houses, offices and farm equipment. Turbines with power capacities between $100 \mathrm{~kW}$ and $1 \mathrm{MW}$ are mid-size, and are normally used to supply power for certain applications in industry and community sectors. Combining these systems has the capability of optimizing grid requirements in remote locations where utility-scale wind plants are not feasible. This method of power distribution adds significantly to the advantages wind energy normally presents as it also alleviates the stress and the pressure on the grid, providing more energy security.

To adopt and encourage the deployment and manufacture of renewable energy technologies in general, and wind systems in particular, governments around the world have offered several incentives and business support to researchers, manufacturers, owners and investors. These can include tax credits, low interest loans, extended period of payment, feed-in tariffs, research grants and carbon credits. The result has been significant growth in the installation of wind turbines, which in turn has challenged industries to extend and enhance their manufacturing capabilities, further reducing cost. This expansion has provided new employment opportunities, public acceptance and development of a competitive market, urging the birth of the next turbine generation. The previous challenges of cost, performance, reliability, size, efficiency, environmental and social issues will be re-addressed.
The deployment of wind power conversion technology requires a deep understanding of a number of various aspects related to design and capabilities of the machines involved. Hence, the development of modern wind turbine technology has evolved over its deployment period and has resulted in three main categories based on the design of the generators used [31-34]. The first generator design is based on a fixed speed wind turbine with a multi stage gearbox and a squirrel cage induction motor (SCIG) with a direct connect to grid (Figure 4). As shown, the SCIG connects directly to the grid via a transformer.

This configuration was initially adopted by Danish manufacturers and hence normally referred to as the Danish concept. This design is well known for its robustness, low cost when mass produced and allows stalls regulated machines to operate at constant speed when connected to large grids hence providing stable control frequency. However, as the speed is constant, this may translate into fatigue and stresses on the machine which in turn may translate into swing oscillations between turbine and generator shaft [3536]. With such design, the rotor is connected to a power electronic converter while the stator winding is directly fed to the grid. This technology comprises a wound rotor induction generator (WRIG) with a limited variable rotor resistance and pitch control arrangement $[35,37]$ (Figure 5) - known as the limited variable speed wind turbines.

The last model fits in the variable speed turbine relying on the use of a doubly fed induction generator (DFIG) multi stage gearbox (Figure 6). In this method,

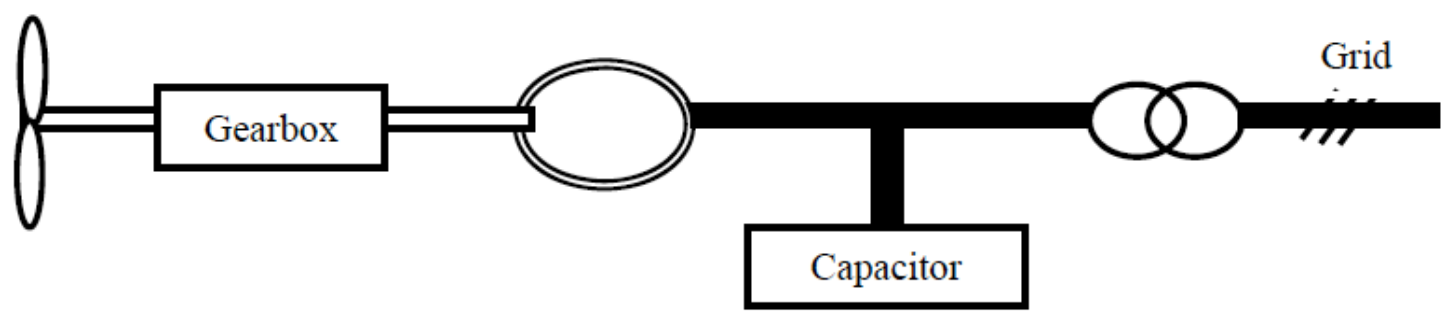

Figure 4: Squirrel Cage Induction Generator Scheme.

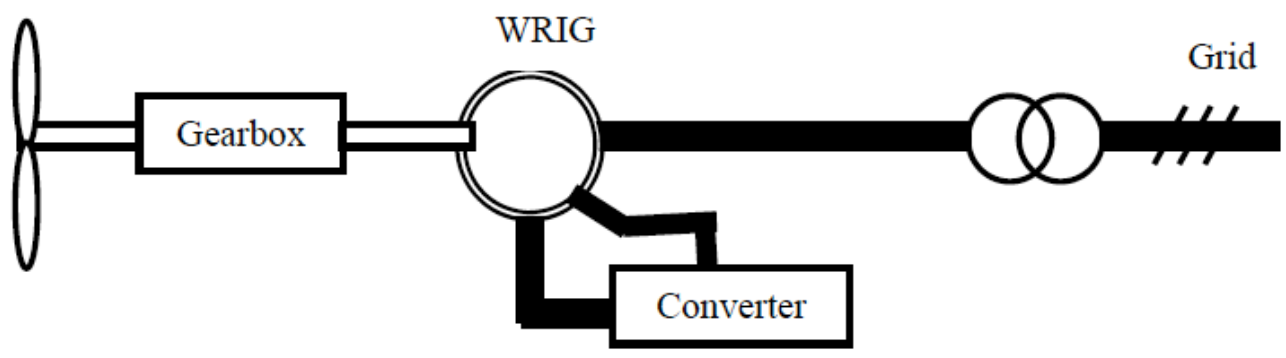

Figure 5: Wound Rotor Induction Generator Scheme. 


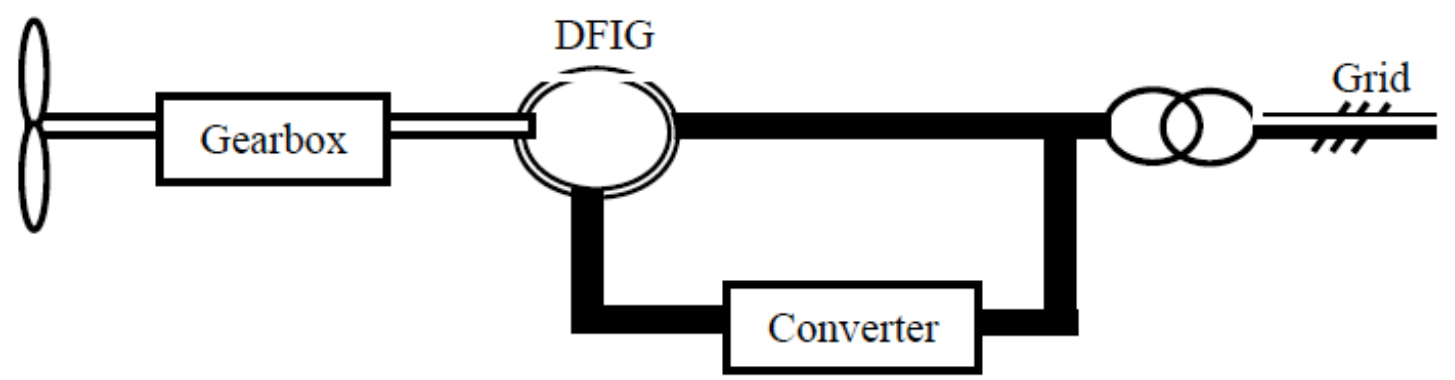

Figure 6: Doubly Fed Induction Generator Scheme.

partial scale frequency converter is used which performs the reactive power conpensation and ensures smoother grid connection. In a high-speed DFIG drivetrain, a slow-turning shaft from the rotor (10-20 rpm) drives a gearbox whose output shaft, rotating at up to $2000 \mathrm{rpm}$, drives the generator. Both rotor and stator use electrically excited (EES) copper windings to create magnetic fields so as the rotor spins, interaction between these fields generates electricity. DFIGs must spin at 750-1500 rpm to operate, hence they are restricted to high-speed applications.

The great advantage of the DFIG is its requirement of a 'partial' (roughly $35 \%$ of the generator's rated capacity) converter because only $25 \%-30 \%$ of the input mechanical energy is fed to the grid through the converter from the rotor while the remaining energy goes directly to the grid from the stator. The efficiency of the DFIG is high as little power is lost via the converter.

To overcome partial scale frequency, it is possible to replace the DFIG with permanent magnet synchronous generator (PMSG) with a full scale converter. This configuration has better efficiency, and allows both $50 \mathrm{~Hz}$ or $60 \mathrm{~Hz}$ grid connection (Figure 7).

Another way to enhance the efficiency and reduce maintenance is to switch to gearless with a direct drive low speed electrically excited synchronous generator. This may be the solution because the generator rotor is directly connected on the hub of the turbine rotor. This technology is characterized with high efficiency, reliability and availability however it has a higher cost and power losses in the power electronics. To increase the efficiency, improve in the thermal characteristics as no field losses take place, obtain higher reliability and lighter technology a permanent magnet synchronous generator (PMSG) can be used with the direct drive arrangement (Figure 8). This means no slip rings or brushes therefore reduced maintenance and greater reliability. The high energy density of permanent helps to deliver a lighter, more compact unit. PMGs are almost as efficient at full-load generation as standard DFIGs but are more efficient at part-loads which is the most common conditions that the wind turbines operate at.

The major disadvantages though are higher cost as PMSG are more expensive as they require expensive rare earth magnets, they also are harder to manufacture and they require demagnetization at high temperature [38-40]. Moreover, issues such as NdFeB magnets' susceptibility to corrosion and their sensitivity to heat are also negative impacts seen in the use of PMSG at high power rated. This trend is currently changing and more current wind power conversion technologies are incorporating permanent magnet generators in their design.

To summarize the various available generator design, Table 1 presents a comparison of the direct

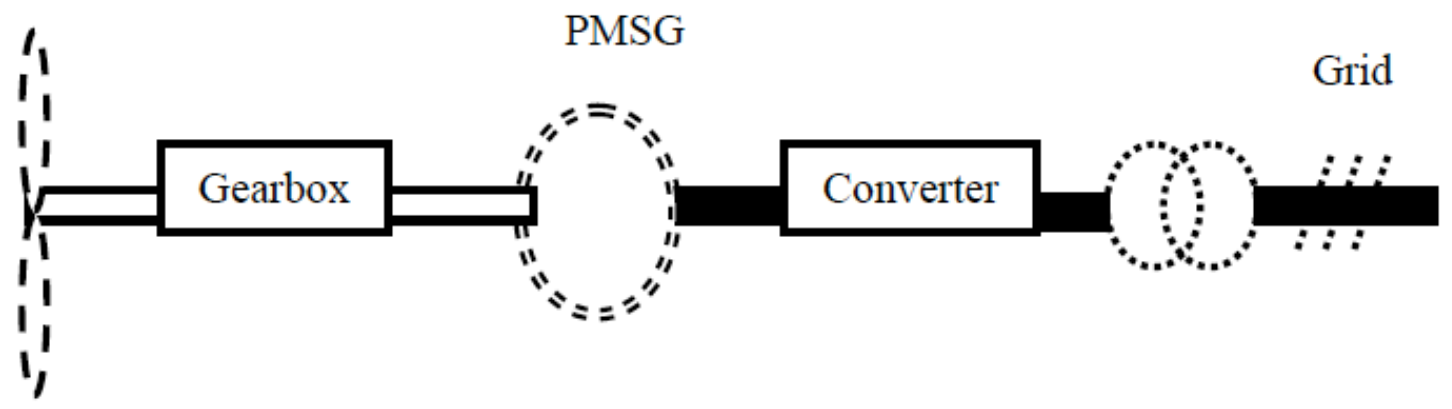

Figure 7: Permanent Magnet Synchronous Generator Scheme. 


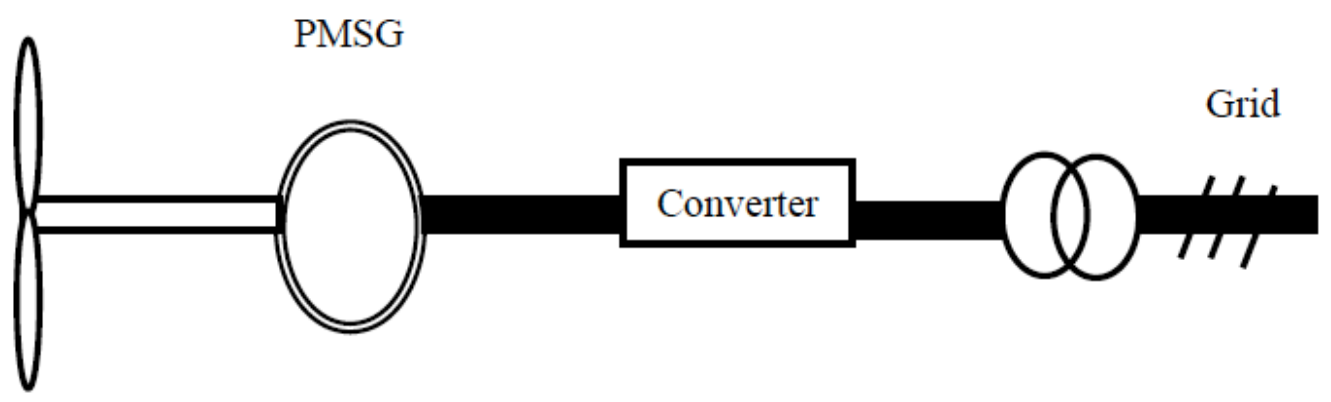

Figure 8: Direct Drive Permanent Magnet Synchronous Generator Scheme.

Table 1: Comparison of Direct Drive PMSG \& Fixed Speed SCIG

\begin{tabular}{|l|c|c|}
\hline Generators Concept & PMSG & SCIG \\
\hline \hline Outer diameter of generator $(\mathrm{m})$ & 2.7 & 1.5 \\
\hline Length of system (incl. high speed shaft in SCIG) $(\mathrm{m})$ & 1.2 & 3 \\
\hline Average Efficiency \% & 90.7 & 88.4 \\
\hline
\end{tabular}

drive PMSG and fixed speed SCIG at $500 \mathrm{~kW}$ power rating [31]. It is obvious that due to its variable frequency capability, direct drive PMSG has the capability of producing higher efficiency thus higher energy yield.

Furthermore, classification of wind conversion technologies can also be achieved based on the control system when power regulation is needed. Such controls are summarized as stall, active stall and pitch control. In case of fixed speed, all three control types were used with the SCIG technology while pitch control has been used with the variable speed generator systems. The next section will give a brief description of the various available control systems.

\section{CONTROL SYSTEMS OVERVIEW}

To illustrate the use of the various control systems, Table 2 represents a summary of the various methods used with the various generator designs.

The fixed speed stall control includes single or two speed stall control concepts. The power limitation over the rated wind speed is undertaken by the stall effect over the rotor blades. Such method is not flexible allowing the blades to rotate at one speed. This in turn affects the efficiency of the blades. This method was also found to cause variation of the active and reactive power from the grid which leads to flickering. To overcome this problem, capacitors were introduced for reactive power compensation in addition to a soft starter circuit to smooth the grid connection of the turbine.

The fixed speed active stall control has the capability to supply power to the grid by rotating the blades which may delay the stall effect. The third control for fixed speed is the pitch control concept which has the opposite turning direction of the rotor blades compared to the other two described methods when regulating wind turbine power. Such method is more suitable for low power wind turbine as larger machines require longer and larger blades which may cause delay in the turning due to high inertia.

In the limited variable speed, the main idea is in the control of the rotor resistance using an external variable resistance. The latter is achieved by mounting an optically power electronics converter on the rotor shaft to control the slip up to $10 \%$ range [41] over the synchronous speed. With such methods, only velocities greater than synchronous speeds are possible, in addition to the fact that this control is dependent on the rotor size.

Table 2: Wind Turbine Control Systems

\begin{tabular}{|c|c|c|c|c|c|c|c|}
\hline \multirow{3}{*}{$\begin{array}{c}\text { Speed } \\
\text { Power regulation } \\
\text { Generator type }\end{array}$} & \multicolumn{3}{|c|}{ Fixed } & \multirow{3}{*}{$\begin{array}{c}\text { Limited Variable } \\
\text { Pitch } \\
\text { WRIG }\end{array}$} & \multirow{2}{*}{\multicolumn{3}{|c|}{$\begin{array}{c}\text { Variable } \\
\text { Pitch }\end{array}$}} \\
\hline & Stall & Active Stall & Pitch & & & & \\
\hline & SGIC & SGIC & SGIC & & DFIG & SGIC & PMSG \\
\hline
\end{tabular}


To enhance the operation, output quality and noise and stress reduction of wind turbines, variable speed wind turbines have been developed. Such technology has the ability to damp the power and torque peaks generated by wind gust while allowing the turbine to accelerate and store energy during gust [42]. To support such operation, pitch control is utilized and is designed based on two methods of operation: speed changes and blade pitch changes. Initially, in order to maintain an optimal tip speed ration between the cut-in speed and rated speed, the equipment is operated at fixed pitch with variable rotor. When rated power is reached, generator torque steps in and controls the electrical output power. During this time, the pitch control maintains the rotor speed within tolerable limits.
During gusts, the generator power can be maintained at a constant level while the rotor speed increases leading to additional kinetic energy stored in the blades. If wind speed decreases, the blades decelerates while the output power remains the same; but if the wind speed stays high, the blade pitch reduces the efficiency of rotor blades and torque leading to reduced rotor speed. This control is used with both DFIG and PMSG configurations.

As several wind turbines have penetrated the market at various power levels and since this paper concentrates on the equipment used for distributed power, selected manufacturers from countries in various worldwide locations for wind turbines ranging

Table 3: Manufacturer's Specifications for Selected HAWT and VAWT

\begin{tabular}{|c|c|c|c|c|c|c|c|}
\hline Manufacture & Type & $\begin{array}{l}\text { Power } \\
\text { Rating } \\
\text { (kW) }\end{array}$ & $\begin{array}{l}\text { Rated } \\
\text { Speed } \\
(\mathrm{mph})\end{array}$ & $\begin{array}{l}\text { Cut-in } \\
\text { Speed } \\
\text { (mph) }\end{array}$ & $\begin{array}{l}\text { Cut-out } \\
\text { Speed } \\
\text { (mph) }\end{array}$ & Generator & Control \\
\hline Proven & HAWT & 12.1 & 24.6 & 7.83 & $\mathrm{~N} / \mathrm{A}$ & & \\
\hline $\begin{array}{l}\text { Gazelle Wind } \\
\text { Turbine }\end{array}$ & $\begin{array}{l}\text { HAWT } \\
3 \text { Blade }\end{array}$ & 20 & 29 & 8.95 & 44.75 & 4 pole & PLC \\
\hline Endurance & $\begin{array}{l}\text { HAWT } \\
3 \text { Blade }\end{array}$ & 50 & 24.6 & 7.8 & 56 & Induction & PLC \\
\hline $\begin{array}{l}\text { Wind Energy } \\
\text { Solution }\end{array}$ & $\begin{array}{l}\text { HAWT } \\
2 \text { Blade }\end{array}$ & 80 & 29 & 6.7 & 56 & Asynchronous & PLC and IPC \\
\hline Enercon & $\begin{array}{l}\text { HAWT } \\
3 \text { Blade }\end{array}$ & 330 & 27.97 & 6.71 & 76.1 & Direct Drive & Active Pitch Control \\
\hline Vestas & $\begin{array}{l}\text { HAWT } \\
3 \text { Blade }\end{array}$ & 850 & 35.8 & 8.95 & 55.9 & $\begin{array}{c}\text { Asynchronous } \\
\text { with Wound Rotor }\end{array}$ & Microprocessor Based \\
\hline Enercon & $\begin{array}{l}\text { HAWT } \\
3 \text { Blade }\end{array}$ & 900 & 33.56 & 8.95 & 76.1 & Direct Drive & Active Pitch Control \\
\hline $\begin{array}{c}\text { Dezhou Xingu } \\
\text { Renewable Energy } \\
\text { Technology }\end{array}$ & $\begin{array}{l}\text { VAWT } \\
3 \text { Blade }\end{array}$ & 10 & 26.85 & 6.71 & 89.5 & & \\
\hline Falcon & $\begin{array}{l}\text { VAWT } \\
3 \text { Blade }\end{array}$ & 12 & 29 & 6 & 11 & $\begin{array}{l}\text { Permanent } \\
\text { Magnet }\end{array}$ & \\
\hline $\begin{array}{c}\text { Energy Research } \\
\text { Development } \\
\text { Cooperation }\end{array}$ & VAWT & 20 & 5.6 & 4.0 & 72 & & $\begin{array}{l}\text { Programmable Flash } \\
\text { Type Control }\end{array}$ \\
\hline $\begin{array}{l}\text { Floating Windfarms } \\
\text { Corporation }\end{array}$ & $\begin{array}{l}\text { VAWT } \\
3 \text { Blade }\end{array}$ & 300 & 44.7 & 14.5 & 53.7 & Induction & \\
\hline
\end{tabular}


from $10 \mathrm{~kW}$ to $1 \mathrm{MW}$ are shown in Table 3. Current information on the important specifications of power rating, rated speed, cut-in speed, cut-out speed, generator and control type is presented. Again confirming that the emphasis has been placed on the research, development and improvement of the horizontal style machines. Note, however, that current research points to a bright future for VAWT as a high power supplier, especially for offshore application.

\section{THE FUTURE OF WECS}

As with all renewable energy technologies, the more advanced that systems becomes the more it will enhance their economic viability, the rate of production and the number of installed turbines. This maturity will ensure that wind energy becomes comparable with traditional sources, causing an increase in demand. However, these fast growing requirements do have some drawbacks, particulary affecting the time available for product test and development phases.

The future of this technology calls for a capability to capture more wind while reducing stresses and losses, hence improving efficiency. Currently, research is focusing on generating lighter, more flexible, noise free turbines using advanced materials and manufacturing processes. Moreover, various control methods to help extract the maximum power from varying wind, so ensuring a fast response to wind fluctuations, are being investigated. For this technology to evolve and become the forerunner for power supply, the study of geographical location, distribution and measurement of wind speed, local wind flow, in addition to wind characteristic parameters, must be accurately assessed.

\section{CONCLUSION}

The growth for energy demand due to technological and demographical expansion has led to more pollution, resulting in global warming associated with many environmental and natural disasters worldwide. To overcome these problems, wind energy has proven to be a green source supplying clean power. This paper has focused on the two most common systems used by the wind industry, HAWT and VAWT, discussing and comparing their advantages and disadvantages, whilst outlining machine specifications from companies which produce wind energy conversion technologies ranging from $10 \mathrm{~kW}-1 \mathrm{MW}$. Some improvements that must be undertaken to overcome current challenges have been highlighted.

\section{REFERENCES}

[1] Abrahensen AB, Mijatovic N, Seiler E, Zirngibl T, Traeholt C, Nogard PB, et al. Superconducting wind turbine generators. Supercond Sci Technol 2010; 23.

[2] Twidell J, Weir A. Renewable Energy Resources, E\&FN Spon, London, UK 1986.

[3] JoselinHerberta GM, Iniyanb S, Sreevalsanc E, Rajapandian S. A Review of wind energy technologies. Renewable Sustainable Energy Rev 2007; 11: 1117-45. http://dx.doi.org/10.1016/j.rser.2005.08.004

[4] Global Wind Energy outlook, Pike research 2011.

[5] Manwell JF, McGowan JG, Rogers AL. Wind Energy Explained Wiley, Amherst, USA 2002. http://dx.doi.org/10.1002/0470846127

[6] Riegler H. HAWT versus VAWT: small VAWTs find a clear niche. Refocus, Bol 2003; 4(4): 44-46.

[7] Sahin A.D. Progress and recent trends in wind energy. Progr Energy Comb Sci 2004; 30: 501-43. http://dx.doi.org/10.1016/j.pecs.2004.04.001

[8] Wind Force, EWEA report, 12, 2002.

[9] Danish Institute of Technology (DTI), Wind turbine survey 1986-1996, Denmark 1992.

[10] Gipe P. Wind Energy Comes of Age, Wiley, New York, USA 1995.

[11] Neij L. Cost dynamics of wind power. Energy 1999; 24: 37589.

http://dx.doi.org/10.1016/S0360-5442(99)00010-9

[12] Thomas BG, Urquhart J. Wind energy for the 1990's and beyond. J Energy Conv Manag 1996; 37(12): 1741.

[13] Wind Power calculation, RWE npower renewables, UK 2003.

[14] Gippe P. Wind Power: Renewable Energy for Home, Farm, and Business, Chelsea Green Publishing Company, 2004; p. 41.

[15] Darrieus GJM. Turbine having its rotating shaft transverse to the flow of the current, US Patent no. 1.835 .018 (1931).

[16] Brothers C. Vertical axis wind turbines for cold climate applications, Renewable Energy Technologies in Cold Climate, Montreal. Private Communication 1998; 2005-0413.

[17] Tucker VA. Using a collision model to design safer wind turbine rotor for birds. J Solar Eng 1996; 118: 263-69. http://dx.doi.org/10.1115/1.2871791

[18] Shankar PN. Development of vertical axis wind turbines Rural Technol Indian Acad Sci 1980; 2(1) 145-62.

[19] Seki K, Simizu Y, Matsumoto T. A study of straight blade VAWT and its application, Proceeding of European Wind Energy Conference, Hamburg, FRG 1984; pp. .436-442.

[20] Paraschivoiu, Wind Turbine Design with Emphasis on Darrieus Concept, Polytechnic International Press, Montréal, Canada 2002.

[21] Vandenberghe D, Dick E. A free vortex simulation method for the straight bladed vertical axis wind turbine. J Wind Eng Indust Aerodynam 1987; 26: 307-24. http://dx.doi.org/10.1016/0167-6105(87)90002-X

[22] Anon. 15. /http://www.windpower.orgS, 2006.

[23] Agren O, Berg M, Leijon M. A time-dependent potential flow theory for the aerodynamics of vertical axis wind turbines. $J$ Appl Phys 2005; 97(10): 104913. http://dx.doi.org/10.1063/1.1896091

[24] Bauer P, de Haan SWH, Dubois MR. Wind energy and offshore wind parks: state of the art and trends, 10th International power electronics and motion control conference, Cavtat\& Dubrovnik, Croatia 2002. 
[25] Eriksson S, Bernhoff $\mathrm{H}$, Leijon M. Evaluation of different turbine concepts for wind power. Renewable Sustainable Energy Rev 2008; 12: 1419-34. http://dx.doi.org/10.1016/j.rser.2006.05.017

[26] How low is a wind turbine?, GE Reports, Nov. 2010 http://www.gereports.com/how-loud-is-a-wind-turbine/

[27] Weiner M. Anti-noise silences wind turbines, Innovations report, 2008. http://test.innovations-report.com/html/reports/ energy_engineering/anti_noise_silences_wind_turbines_115 921.html

[28] Ackerman T, Soder L. Wind energy technology and current status: A review. Renewable Sustainable Energy Rev 2000; 4(4): 315-74. http://dx.doi.org/10.1016/S1364-0321(00)00004-6

[29] Robert WT, Darrell MD. Trends in the evolution of wind turbine generator configurations and systems. Wind Energy 1998; 1(1): 70-85.

http://dx.doi.org/10.1002/(SICl)10991824(199804)1:1+<70::AID-WE2>3.3.CO;2-0

[30] Peace S. Another approach to wind (cover story). Mech Eng 2004; 126(6): 28-31.

[31] Li H, Chen Z. Overview of different wind generator systems and their comparisons. IET Renewable Power Generation 2008; 2(2): 123-38. http://dx.doi.org/10.1049/iet-rpg:20070044

[32] Hansen AD, Hansen LH. Wind turbine concept market penetration over 10 years (1995-2004). Wind Energy 2007; 10(1): 81-97. http://dx.doi.org/10.1002/we.210

[33] Chen Z, Blaabjerg F. Wind turbines -a cost effective power source. Przeglad Elektrotrchniczny 2004; 80(5): 464-69.
[34] Harrison R, Hau E, Snel L. Large wind turbine design and economics, John Wiley \& Sons 2000.

[35] Hanse LH, Helle L, Baabjerg F, et al., Conceptual survey of generators and power electronics for wind turbines, Riso National Laboratory Technical report Riso-R-1025, Roslikidle, Denmark. December 2001.

[36] Polinder H, Moren J. Developments in wind turbine geberator systems, Electrimacs, Hmammamet, Tunisia 2005.

[37] Dubois MR, Polinder H, Ferreira JA. Comparison of generator topologies for direct drive wind turbines. Proc Nordic Countries Power and Industrial Electronics Conf Aalborg, Denmark, 2000; pp. 22-26.

[38] Dubois MR. Optimized permanent magnet generator topologies for direct drive wind turbines, Ph.D. dissertation, Delft University Technology, Thte Netherlands 2004.

[39] Chen Y, Pillay P, Khan A. PM wind generator topologies. IEEE Trans Indus Appl 2005; 41(6): 1619-26. http://dx.doi.org/10.1109/TIA.2005.858261

[40] Hanitsch R, Korouji G. Design and constructing of a permanent magnet wind energy generator with a new topology, KOMEL Conf., Poland 2004; pp. 63-66.

[41] Chen Z, Blaabjerg F. Wind Energy-The World's Fastest Growing Energy Source. IEEE Power Electronics Society Newsletter 2006; 18(3).

[42] Vihriälä H. Control of variable speed wind turbines, Ph.D. dissertation Tampere University of Technology, Hervanta, Finland 2002. 